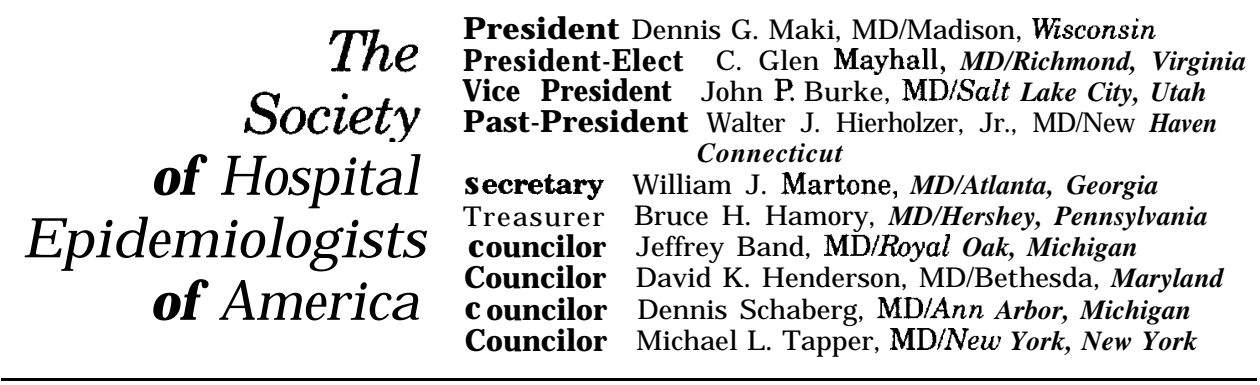

\section{Year 2000 Health Objectives}

Dr. C. Glen Mayhall will represent SHEA at the upcoming invitational conference being convened by the Secretary of Health and Human Services in Washington, D.C., September 6-7, to launch "Healthy People 2000: National Health Promotion and Disease Prevention Objectives."

Dr. Mayhall represented SHEA in October at the initial "Year 2000 Health Objectives Consortium Meeting" that provided a forum for public comment on the draft of the "Objectives" that had been formulated by the U.S. Public Health Service. A summary of Dr. Mayhall's comments was reported in the February Newsletter.

\section{SHEA Annual Meeting}

The annual SHEA luncheon meeting will be held in Atlanta, Georgia on Tuesday, October 23, 1990 during the Interscience Conference on Antimicrobial Agents and Chemotherapy (ICAAC). Please plan to attend. Look for further details with your SHEA ballot and in the September issue of the Newsletter.

\section{SHEA Elections}

If you are a member of SHEA and do not receive the ballot for the upcoming SHEA election by August 31, please contact the SHEA Secretary, Dr. William Martone, Centers for Disease Control, Bldg. 1, Mailstop C-10, Room 5065, 1600 Clifton Road, NE, Atlanta, GA 30333.

\section{Position Paper Committee}

Dr. C. Glen Mayhall reports the following activities of the SHEA Position Paper Committee. First, the joint SHEA/APIC task force that is preparing a position paper on the human immunodeficiency virus-(HIV) infected healthcare worker is in the process of finalizing its recommendations. Second, the SHEA task force on medical waste disposal is being reformulated, and guidelines are still in the works. Finally, a task force has been named to prepare a position paper on surveillance for surgical wound infections under Dr. Robert Sherertz, chair.

\section{Oral Hygiene Irrigation Device-Related Tuberculosis}

Many an "exposure list" has been generated by hospital admission of a patient with unrecognized pulmonary tuberculosis. It appears that we may now have to worry about communicability from soft tissue infections with tuberculosis as well. Hutton, Stead and associates reported in a recent issue of the Journal of Infectious Diseases (1990;161:286295) that nine cases of pulmonary tuberculosis and 59 skin test conversions occurred among personnel exposed to a patient hospitalized with a large tuberculous abscess of the hip and thigh. The authors postulate that high concentrations of Mycobacterium tuberculosis in the abscess, aggressive irritation of the abscess cavity with an oral hygiene water irrigation device and the positive air pressure in the patient's room 
contributed to the high rate of transmission.

In simulation studies with the oral hygiene irrigation device, approximately $4 \%$ of an irrigating solution was aerosolized into droplets with the 1-to-200 $\mu$ range. The authors note that droplets of this size can evaporate rapidly to form droplet nuclei within the respirable range of $1 \mu$ to $5 \mu$.

Although this case is distinctly unusual-it is in fact the first report to the authors' knowledge of airborne transmission of tuberculosis from a living patient who did have respiratory tract or oral cavity involvement-it shows that the creation of novel nosocomial infectious diseases knows no bounds.

Brief items of interest for the SHEA Newsletter may be sent to Robert A. Weinstein, MD, SHEA Newsletter Editor, Division of Infectious Diseases, Michael Reese Hospital, Lake Shore Drive at 31st St., Chicago, IL 60616. Copy must be typed, doublespaced and may not exceed five pages.

\section{Membership Application Inquiry:}

Mail to: Secretary

Society of Hospital

Epidemiologists of America

c/o Slack, Incorporated

6900 Grove Road

NAME:

Thorofare, NJ 08086

\section{ADDRESS:}

Doctoral Degree _ MD _ PhD

Date and University:

Specify work in hospital epidemiology and related fields:

Dates in this position:

Related work in the field:

( ) Check type of membership application:

I - Active Membership

(Calendar year dues \$75)

- Associate Membership

(Calendar year dues (\$35) 